\title{
CUSUM based Fault Detection of Stator Winding Short Circuits in Doubly-Fed Induction Generator based Wind Energy Conversion Systems
}

\author{
Jawwad Zafar, Johan Gyselinck \\ Department of Electrical Engineering \\ Université Libre de Bruxelles (ULB) \\ CP165/52, 50 Av. F.D. Roosevelt, 1050 Brussels, Belgium. \\ Phone: +32 2650 2660, Fax: +32 2650 2653, e-mail: Jawwad.Zafar@ulb.ac.be
}

\begin{abstract}
This paper investigates the detection of shortcircuit faults in the stator winding of a Wind Energy Conversion System (WECS) based on a Doubly-Fed Induction Generator (DFIG). The Cumulative Sum (CUSUM) algorithm is used to detect the change in the stator negative-sequence current magnitude which is used as the fault residual. The grid voltage unbalance is considered along with the fault position and its severity to evaluate the effect on the residual. The generator is modeled using the winding-function approach. Simulation results are presented for a $15 \mathrm{~kW}$ system operated, under a power control strategy, at rated conditions. It is shown that the fault-detection method is able to detect the fault rapidly and is not influenced by the grid voltage unbalance within normal limits.
\end{abstract}

\section{Key words}

Short circuits, DFIG, CUSUM, Winding-function theory

\section{Introduction}

Fault detection in Wind Energy Conversion Systems (WECS) has been gaining pace over the years. As more and more offshore wind farms are envisaged accessibility, monitoring and maintenance costs become all the more important issues. WECSs based on the Doubly-Fed Induction Generator (DFIG) are a popular choice now-a-days for offshore installations. Such a system is therefore selected as the target system and analyzed to validate the fault-detection approach.

Stator winding short-circuit faults comprise around $40 \%$ of all machine faults [1]. It is necessary to detect this type of fault, as soon as possible, since it has the potential to develop into a catastrophic system failure with the eventual damage to the generator core. It is widely believed that a winding short-circuit fault, be it a phasephase or phase-ground fault, starts as a turn-turn fault [1]. Therefore, in this paper such a winding fault in the coil of a stator phase winding is investigated.

Recently some papers have studied the stator shortcircuit fault detection in DFIG based WECSs [2]-[5]. All of them use Current Signature Analysis (CSA) techniques to detect certain frequency components that appear in case of such a fault. This method of fault detection is computation intensive and it has not been shown how rapidly this critical fault is detected. In all but [3] the experimental results have been obtained by paralleling a resistance with a phase winding to create an unbalance. This does not represent the true fault condition because internal construction of the machine does not change; only a new circuit is added. In fact it is reported in [3] that opposite results for current magnitudes and phase angles are obtained, to what are expected with the model, using this method. Negativesequence current as a fault residual has been used for motors previously [6]-[8]. It is easily computed but is affected by factors such as the terminal voltage unbalance, transducer gain etc. In this paper it is combined with an easily implementable change detection algorithm known as the Cumulative Sum (CUSUM) algorithm and it is shown that faults are detected within a couple of cycles of the fundamental frequency. The system is modeled in sufficient detail to given an idea of how much of residual change is expected, at an operating point, when the fault occurs and the resulting detection 
system is tested against different conditions of noise and grid-voltage unbalance.

\section{Description of the system}

The DFIG system considered is operated under an active control which means that the control will respond to the appearance of the fault condition. This is important to consider since the way the fault manifests itself in the currents may be modified by the control action. A powercontrol strategy is used whereby the system generates rated active power, at the point of common coupling, while the reactive power is maintained at zero. A secondorder filter with a cut-off frequency of $500 \mathrm{~Hz}$ is used on the measurements which are contaminated with a Gaussian noise of $1 \%$ variance of the rated current value.

A multiple-coupled circuit model using the windingfunctions approach is developed for the generator [9]. The effect of space harmonics is thus included while the standard assumption of an unsaturated core is taken. The wound-rotor induction generator is a 3-phase, 4-pole, 36 stator slots machine and has a single-layered lap-wound winding with gives 6 coils per phase. The stator core is shown in Figure-1and the parameters of the machine are given in the Appendix. A bolted fault is created in one coil at a time, out of the three for a pole pair, of the same phase and the effect of position and severity are observed on all the phase current magnitudes. It is expected that the orientation of this high current shorted-turns loop has an effect on the phase currents. The faults in the coils of the other pole pair will give the same results since no construction asymmetry is present.

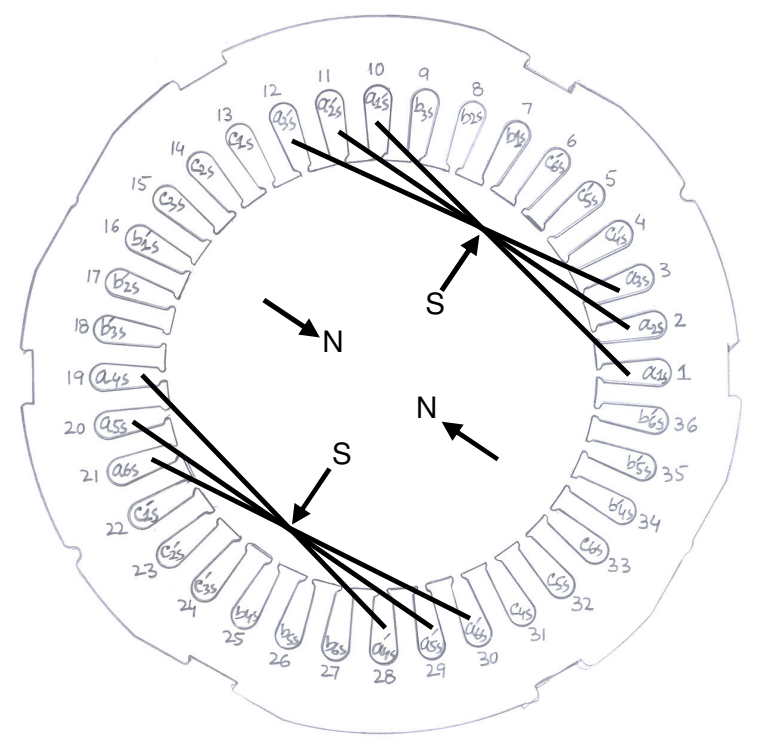

Figure 1 - Stator core showing one phase winding.
This model provides the possibility to study the effects of fault position and its severity on the negative-sequence stator current and thus on the detection of the fault.

Negative-sequence currents arise in this system due to construction asymmetry, faults, transducer-gain difference, voltage and load unbalance at the terminals. Since the proposed method is based on the magnitude of the negative-sequence current, it is therefore necessary to take these factors into account. In the present work the effect of grid voltage unbalance is included in the investigation while the other factors are assumed not to have a large impact on the negative-sequence current magnitude. The symmetrical components are calculated as

$$
\left[\begin{array}{c}
i_{+} \\
i_{-} \\
i_{0}
\end{array}\right]=1 / 3\left[\begin{array}{ccc}
1 & a & a^{2} \\
1 & a^{2} & a \\
1 & 1 & 1
\end{array}\right]\left[\begin{array}{c}
i_{a} \\
i_{b} \\
i_{c}
\end{array}\right]
$$

$i_{+}, i_{-}, i_{0}$ are the positive, negative and zero-sequence current components respectively. $i_{a}, i_{b}, i_{c}$ are the phase currents and $a=e^{j 2 \pi / 3}$.

\section{Simulation Results}

Simulations are performed for different fault locations and severity.

\section{A. Residual Generation}

Table-1 summarizes the results for a balanced grid voltage. Only two of the phase currents are listed. The third one will just be the negative sum of the other two since the neutral point is not connected. It is found that the current in the shorted turns is reduced as the fault level is increased from half a coil to full coil. The reason is that the voltage induced in the shorted turns is proportional to the number of turns while the total reactance of the turns is proportional to the square of the number of turns [3]. There is no effect on the phase currents with severity however. This is due to the presence of the control system which has an effect on the magnitude and also reduces the unbalance between the phase currents. It can also be concluded from this that a fault involving fewer turns than the equivalent of half a coil will also give the same phase current magnitudes. The fault location, on the other hand, has a larger impact on the current with a difference of as much as $2.5 \mathrm{~A}$ in the faulted-phase (phase-A) current for different locations. 
Table 1 - Stator currents for balanced grid voltages at different faults

\begin{tabular}{|c|c|c|c|c|c|}
\hline \multicolumn{6}{|c|}{ Balanced Grid Voltage } \\
\hline $\begin{array}{c}\text { Fault } \\
\text { Case }\end{array}$ & $\begin{array}{c}- \text { ve } \\
\text { seq } \\
\text { current } \\
\text { [A] }\end{array}$ & $\begin{array}{c}\text { + ve } \\
\text { seq } \\
\text { current } \\
\text { [A] }\end{array}$ & $\begin{array}{c}\text { Stator } \\
\text { ph-A } \\
\text { current } \\
\text { [A] }\end{array}$ & $\begin{array}{c}\text { Stator } \\
\text { ph-B } \\
\text { current } \\
\text { [A] }\end{array}$ & $\begin{array}{c}\text { Shorted- } \\
\text { turns } \\
\text { current } \\
\text { [A] }\end{array}$ \\
\hline $\begin{array}{c}\text { No } \\
\text { fault }\end{array}$ & 0.09 & 32.44 & 32.42 & 32.42 & 0.0 \\
\hline $\begin{array}{c}1 / 2 \\
\text { coil-1 }\end{array}$ & 2.06 & 32.56 & 31.12 & 34.52 & 117.2 \\
\hline $\begin{array}{c}\text { Full } \\
\text { coil-1 }\end{array}$ & 2.17 & 32.57 & 31.14 & 34.66 & 68.4 \\
\hline $\begin{array}{c}1 / 2 \\
\text { coil-2 }\end{array}$ & 2.00 & 32.55 & 32.29 & 34.41 & 106.6 \\
\hline $\begin{array}{c}\text { Full } \\
\text { coil-2 }\end{array}$ & 2.12 & 32.57 & 32.33 & 34.52 & 59.8 \\
\hline $\begin{array}{c}1 / 2 \\
\text { coil-3 } \\
\text { coil-3 }\end{array}$ & 2.07 & 32.54 & 33.59 & 33.60 & 102.7 \\
\hline
\end{tabular}

The positive and negative-sequence currents are also calculated as listed in Table-1. The word 'residual' is used henceforth instead of the negative-sequence current magnitude. In the no-fault case, with a balanced grid, the residual mean value is very small. It is not exactly zero due the presence of space harmonics and noise. When the fault occurs this mean value rises to $2 \mathrm{~A}$. It is seen that the effect of the fault is to add a negative-sequence current while the positive-sequence current remains the same. This is easily explained since a power-control strategy is used which ensures that the positive-sequence current magnitude and phase before and during the fault remain the same. As already mentioned factors other than the faults can also lead to negative-sequence currents in the machine. It is stated in literature that the grid voltage unbalance adds a negative-sequence current to the system that is almost independent, provided few turns are shorted so that the negative-sequence impedance does not change [1]. This add-on effect was analyzed since then it could be directly compensated to make the residual only fault dependent.

Table-2 lists the results with an unbalanced condition for the grid voltage quantized by a Voltage Unbalance Factor (VUF). The VUF is defined as the ratio between the negative-sequence and the positive-sequence components of the voltage [10]. This VUF of $3 \%$ gives a residual mean value of $0.4 \mathrm{~A}$ in the absence of a fault.

Table 2 - Stator currents for unbalanced grid voltages at different faults

\begin{tabular}{|c|c|c|c|c|c|}
\hline \multicolumn{5}{|c|}{ Unbalanced Grid Voltage (VUF 3 \%) } \\
\hline $\begin{array}{c}\text { Fault } \\
\text { Case }\end{array}$ & $\begin{array}{c}\text { - ve seq } \\
\text { current } \\
\text { [A] }\end{array}$ & $\begin{array}{c}\text { + ve } \\
\text { seq } \\
\text { current } \\
\text { [A] }\end{array}$ & $\begin{array}{c}\text { Stator } \\
\text { ph-A } \\
\text { current } \\
\text { [A] }\end{array}$ & $\begin{array}{c}\text { Stator } \\
\text { ph-B } \\
\text { current } \\
\text { [A] }\end{array}$ & $\begin{array}{c}\text { Shorted- } \\
\text { turns } \\
\text { current } \\
{[\text { A }]}\end{array}$ \\
\hline $\begin{array}{c}\text { No } \\
\text { fault }\end{array}$ & 0.40 & 32.42 & 32.00 & 32.69 & 0.0 \\
\hline $\begin{array}{c}1 / 2 \\
\text { coil-1 }\end{array}$ & 2.45 & 32.67 & 30.84 & 34.79 & 117.0 \\
\hline $\begin{array}{c}\text { Full } \\
\text { coil-1 }\end{array}$ & 2.58 & 32.67 & 30.84 & 35.14 & 67.73 \\
\hline $\begin{array}{c}1 / 2 \\
\text { coil-2 }\end{array}$ & 2.24 & 32.61 & 31.96 & 34.79 & 108.6 \\
\hline $\begin{array}{c}\text { Full } \\
\text { coil-2 }\end{array}$ & 2.37 & 32.62 & 31.98 & 34.92 & 60.12 \\
\hline $\begin{array}{c}1 / 2 \\
\text { coil-3 } \\
\text { Fuil-3 }\end{array}$ & 2.04 & 32.51 & 33.18 & 33.89 & 106.1 \\
\hline
\end{tabular}

The results show that although the residual mean does increase for two of the fault positions, coil-1 \& 2, it is not simply an add-on effect. In fact for one of the fault positions, coil-3, there is no effect of voltage unbalance on the residual mean value at all. Thus it cannot be directly compensated here. It is however noted that the difference in residual mean value for different fault locations is larger in the presence of unbalance than the case of balanced grid voltages.

\section{B. CUSUM Algorithm}

The CUSUM algorithm can be used for the residual change-detection [11]. It assumes that the residual has the same variance before and during the fault while only its mean value changes. The cumulative sum, $S_{k}$ of the Log-Likelihood Ratio (LLR), $s_{i}$ is given as:

$$
S_{k}=\sum_{i=1}^{k} S_{i}
$$


$i=1 \ldots k$ is the sample number. The LLR itself is defined as

$$
s_{i}=\frac{\theta_{1}-\theta_{0}}{\sigma^{2}}\left(y_{i}-\frac{\theta_{1}+\theta_{0}}{2}\right)
$$

$\theta_{0}, \theta_{1}$ are the mean values of the residual before and after the fault. $\sigma, y_{i}$ are the variance and sampled value of the residual. $S_{k}$ has a negative drift in the absence of the fault and vice versa. The test function $g_{k}$ is given as

$$
g_{k}=\sup \left(0, g_{k-1}+s_{k}\right)
$$

It is a recursive computation. The alarm will be generated when $g_{k}$ exceeds a specified threshold given as $h$. The time to the alarm $t_{a}$ is thus defined as

$$
t_{a}=\min \left\{k: g_{k} \geq h\right\}
$$

It is required to select the threshold such that fast detection time is achieved in case of fault while false alarms are avoided. A simple way to select the threshold that is expected to give a detection time equivalent to about one cycle is given as

$$
h=a b s\left(s_{1}\right) \cdot\left(\frac{1}{f . T_{s}}\right)
$$

$f, T_{s}$ are the fundamental frequency and the sampling time.

\section{Validation}

A validation of the detection method is carried out by fault simulations with different noise characteristics. Here a residual mean value of at least $2.0 \mathrm{~A}$ is expected after the fault event. The threshold is selected as in (6). Since the residual can also be affected by voltage unbalance, a test with a VUF of $6 \%$ is also carried out. The voltage unbalance at the terminals of an induction machine leads to increased heating losses and requires derating therefore the unbalance is normally restricted to below $5 \%$ as per NEMA guidelines [10]. The VUF taken for the validation should therefore suffice.

The results of one of the simulations are presented in the following figures. The system is operated at rated conditions. A half-coil fault is created at $0.5 \mathrm{~s}$. The stator and short-turns current are shown in Figure-2a. The shorted-turns current has a peak value of about $120 \mathrm{~A}$.
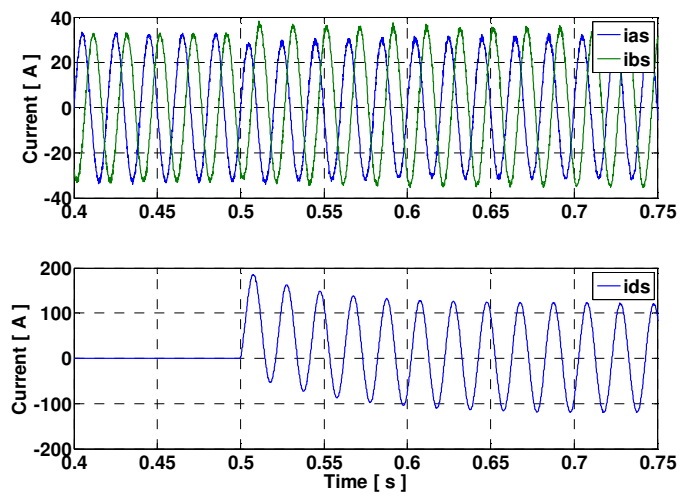

(a)
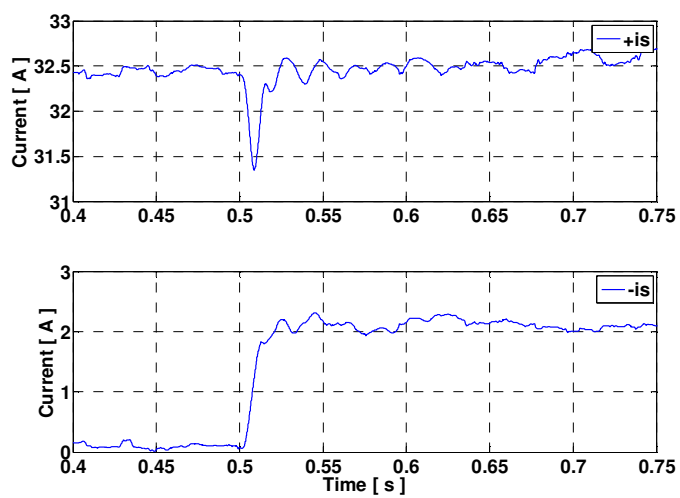

(b)

Figure 2 - Stator currents. (a) phase currents ias, ibs and shorted-turns current ids. (b) positive sequence $+i s$ and negative sequence -is currents.

The positive and negative-sequence current components are shown in Figure-2b. It takes around one cycle worth of time, from the start of the test, to determine their values since the phasors need to be calculated. As mentioned earlier due to the effect of power control the positive-sequence component achieves the same magnitude, as before the fault, after a small transient. The negative-sequence component however changes its magnitude permanently and is the residual. The detection system performance is shown in Figure-3. An alarm is raised when the test function reaches the threshold value. It is then reset to zero to avoid large values. The y-axis scaling has been adjusted to clearly show the different variables in the figure. Although the use of filters causes a detection delay the fault is detected $32 \mathrm{~ms}$ from its occurrence and the alarm is generated. This is still more than what was designed for but since the residual has a variance the slope of the integration is not constant and it 
takes half a cycle longer to detect the fault.

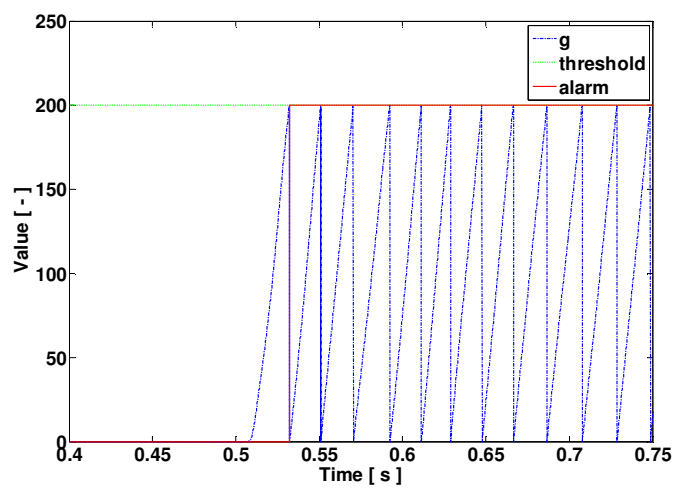

Figure 3 - Performance of the detection algorithm.

Other quantities from the same test are presented in Figure-4. It is seen in Figure-4a that additional harmonics are introduced in the rotor currents while its magnitude is not affected much. There is an increase in the magnitude of the electromagnetic torque oscillations as shown in the same figure.
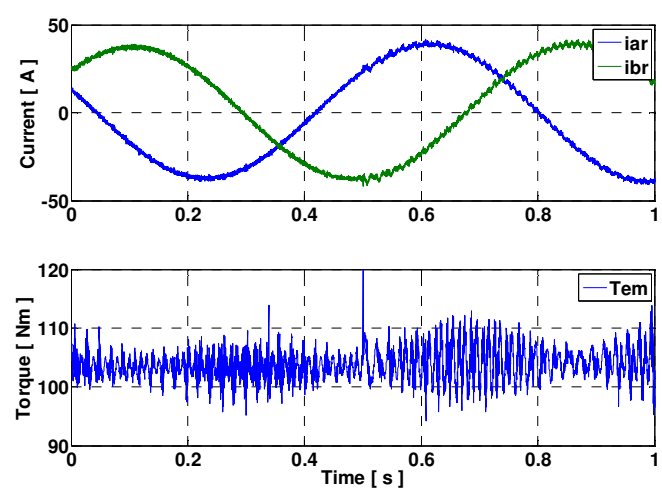

(a)
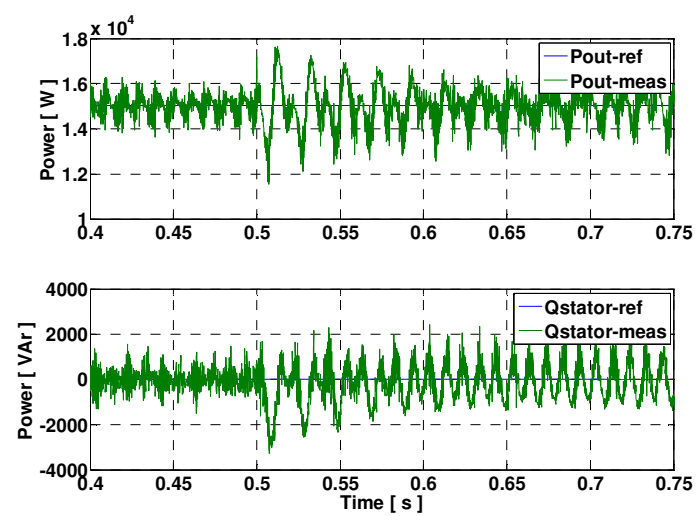

(b)

Figure 4 - Electrical quantities. (a) rotor currents iar, ibr and electromagnetic torque Tem. (b) Active power Pout and reactive power at the stator $Q$ stat.
The total active power sent to the grid and the reactive power at the stator terminals is shown in Figure-4b.

In all of the simulations done for validation the detection time was less than $40 \mathrm{~ms}$. The test with a VUF of $6 \%$ gives a residual mean value of $0.7 \mathrm{~A}$ which was not able to generate an alarm. It is therefore concluded that the detection method is robust to voltage unbalance within the NEMA limit of $5 \%$.

\section{Conclusion}

This paper presents the CUSUM algorithm as a change detection tool which gives robust fault detection against normal terminal voltage unbalance that affects the residual. It is easily implemented and provides rapid fault detection of within 2 cycles of the fundamental frequency. It is however necessary to study the method for different operating points to select the proper threshold.

\section{Appendix}

DFIG Parameters:

Rated Power $P_{\text {rated }}=15 \mathrm{~kW}$

Rated Voltage $V_{r m s}=400 \mathrm{~V}$

Stator Resistance $R_{s}=0.2147 \Omega$

Stator Leakage Inductance $L_{l s}=9.91 \mathrm{e}^{-4} \mathrm{H}$

Rotor Resistance $R_{r}=0.2205 \Omega$

Rotor Leakage Inductance $L_{l r}=9.91 \mathrm{e}^{-4} \mathrm{H}$

Mutual Inductance $L_{m}=0.06419 \mathrm{H}$

Inertia $J_{e q}=0.102 \mathrm{Kg} \cdot \mathrm{m}^{2}$

\section{Acknowledgement}

This work was performed in the framework of a Concerted Research Action supported financially by the "Ministère de la Communauté Française - Direction Générale de l'Enseignement Non Obligatoire et de la Recherche Scientifique". The scientific responsibility rests with the authors.

\section{References}

[1] G.B. Kliman, W.J.Premerlani, R. A. Koegl and D. Hoeweler, "A New Approach to On-line Turn Fault Detection in AC Motors", Conference Record of the IEEE Industry Applications Society, vol. 1, pp. 687693, 1996. 
[2] D. Shah, S. Nandi, P. Neti, "Stator Inter-turn Fault Detection of Doubly-Fed Induction Generators Using Rotor Current and Search Coil Voltage Signature Analysis", Conference Record of the IEEE Industry Applications, $42^{\text {nd }}$ IAS Annual Meeting, pp 1948-1953, 2007.

[3] Q. F. Lu, Z. T. Cao, E. Ritchie, "Model of Stator Inter-turn Short Circuit Fault in Doubly-fed Induction Generators for Wind Turbine", $35^{\text {th }}$ Annual IEEE Power Electronics Specialists Conference, 2004.

[4] H. Douglas, P. Pillay, P. Barendse, "The Detection of Interturn Stator Faults in Doubly-Fed Induction Generators", $40^{\text {th }}$ IAS Industry Applications Conference, 2005.

[5] L. M. Popa, B.-Bak Jensen, E. Ritchie, I. Boldea, "Condition Monitoring of Wind Generators", $38^{\text {th }}$ IAS Industry Application Conference, 2003.

[6] R. M. Tallam, D. J. Gritter, B. H. Burton, "Neural Network based On-line Stator Winding Turn Fault Detection for Induction Motors", Conference Record of the IEEE Industry Applications Conference, vol. 1, pp. 375-380, 2000.
[7] Q. Wu, S. Nandi, "Fast Single-turn Sensitive Stator Inter-turn Fault Detection of Induction Machines Based on Positive and Negative Sequence Third Harmonic Components of Line Currents", IEEE Industry Application Society (IAS) Annual Meeting, 2008 .

[8] J. Quiroga, Li Lui, D. A. Cartes, "Fuzzy Logic based Fault Detection of PMSM Stator Winding Short under Load Fluctuation using Negative Sequence Analysis", 2008 American Control Conference, Seattle, Washinton, USA.

[9] N. A. Al-Nuaim, H. A. Toliyat, "A Novel Method for Modeling Dynamic Air-Gap Eccentricity in Synchronous Machines Based on Modified Winding Function Theory", IEEE Transactions in Energy Conversion, Vol. 13, No. 2, June 1998.

[10] K. V. Vamsi Krishna, "Effects of Unbalance Voltage on Induction Motor Current and its Operational Performance”, Lecon System.

[11] M. Kinnaert, D. Vrancic, D. Denolin, D. Juricic, J. Petrovcic, "Model-based Fault Detection and Isolation for a gas-liquid separation unit", Control Engineering Practice, Elsevier Science Ltd., 2000. 